\title{
Laboratory control of behavior without laboratory restraint
}

RICHARD F. SMITH

INDIANA UNIVERSITY

\begin{abstract}
Abstraet
Wild deer mice (Peromyscus maniculatus) were conditioned to enter an experimental chamber placed in their natural environment and bar press for food on FR 5. Time spent in the chamber, responses, and reinforcements were recorded per chamber entry. The quantitative measurement of behavior parameters in this fashion might resolve one difference in research preference between ethologists and experimental psychologists.
\end{abstract}

\section{Problem}

A general difference in behavioral research strategy exists between American animal psychologists and European ethologists. This is largely a difference between the American emphasis on studying domesticated animals in a strictly confined environment where quantitative records of behavior can be automatically obtained, and the European emphasis on the importance of naturally occurring behavior as observed in the undomesticated animal's natural habitat. Kavanau, for example, remarks that "Domestic animals remain convenient vegetalized strains for physiological studies, but only wild animals provide the full range and vigor of responses upon which solutions to the central problems of behavior must be based。" (1964, p. 490). In summarizing the American viewpoint at a meeting of ethologists and experimental psychologists held in Rome in 1964, Schoenfeld \& Baron (1965) indicate the Americans felt that specifiable conditions and the isolation of experimenter selected behaviors required and justified laboratory research.

A technique that provides quantitative data from arbitrary or natural behaviors, permits environmental stimulus control, and can be applied in the S's natural habitat should create an important area of research. If the relationships expounded by American learning theory cannot be extrapolated beyond the laboratory, they are clearly of little value in "explaining" behavior. If these relationships do hold in the field, the ethologists might better start building Skinner boxes and save shoe leather.

The emphasis in the current work is on the feasibility of conditioning animals and remotely recording their behavior without capturing them or restricting their normal environment.

\section{Method}

The apparatus consisted of a chamber 6 in wide, 5 in long, and 4 in high. The chamber was equipped with a bar requiring a force of $1 \mathrm{gm}$ for activation of recording apparatus. No response feedback was presented in the box, although the recording apparatus could be heard a few yards away. Food pellets (Noyes, $45 \mathrm{mg}$ ) were delivered from a Davis pellet dispenser to a food cup located near the bar. A pair of one-way doors at the entrance determined the direction of movement through the test chamber. By electromagnetically locking the first entrance door when the second entrance door was opened, it was possible to permit only one animal in the chamber at a time. A pair of one-way exit doors insured against return of the mouse to chamber, i.e., if the second door opened one could be certain that the first exit door had been passed. Displacement of the second exit door activated a printout counter, thus registering data on a behavior per visit basis. At the time the research was conducted it was not possible to identify specific individuals. Initially animals were placed on continuous reinforcement (CRF). The requirement was later raised to fixed ratio five (FR 5). Higher schedules were successfully applied, but the sudden reduction of the mouse population with the onset of spring resulted in little data on these schedules. The author's mouse infested cabin in Southern Indiana provided the research space.

\section{Results and Diseussion}

An example of the behavior resulting from FR 5 early in conditioning appears in Fig. 1. Each cumulative record represents data from a single entry. The postreinforcement pauses followed by constant terminal rates are typical of behavior obtained in laboratory animals under similar schedules of reinforcem (Ferster \& Skinner, 1957).

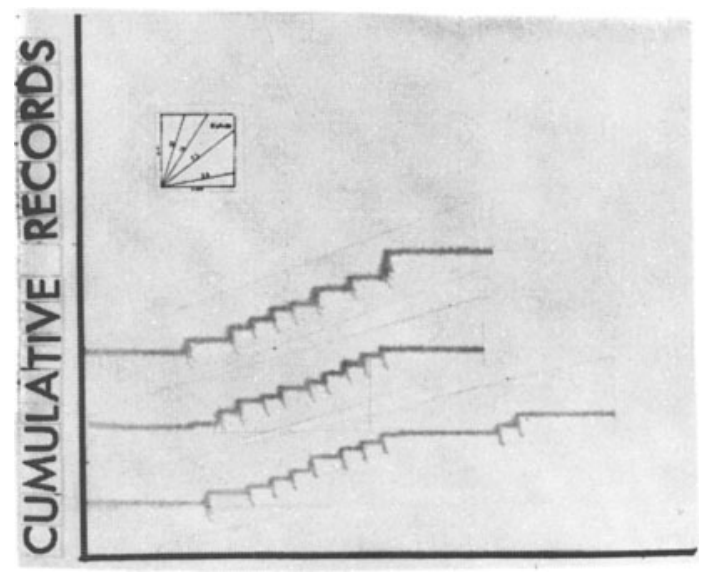

Fig. 1. Cumulative records showing early FR 5 performance. Downward deflections indicate reinforcement. 


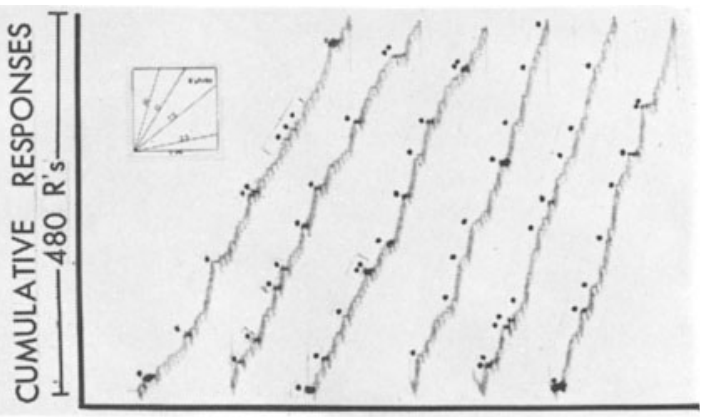

Fig. 2. Final behavior on FR 5. Downward deflections indicate reinforcement. Marks above record indicate time of exit from chamber.

A sample of the final behavior obtained on the FR 5 schedule appears in Fig. 2. Marks above the record indicate successive visits to the chamber. Changes in response rate between visits may indicate the presence of different mice.

Although the large number of reinforcements obtained per day indicates that the population of conditioned mice was large, our inability to identify individuals made population size difficult to estimate. Periodic observation of paper located under the chamber revealed considerable deposits of food crumbs, indicating that the mice ate the pellets in the chamber rather than hoarding them.

Table 1 presents data on the distributions of response rate, time spent in the chamber, and total number of responses emitted per entry for two successive $24 \mathrm{hr}$. periods.

Table 1. Summary Data from Entries Occurring in a $48 \mathrm{hr}$ Period

\begin{tabular}{lrrrr} 
& \multicolumn{4}{l}{$($ Time in sec., $N=259)$} \\
Measurement & Mean & \multicolumn{1}{c}{ SD } & Max & Min \\
\hline Responses & 28.78 & 44.15 & 379.00 & 0.00 \\
Time in Box & 72.09 & 96.48 & 777.00 & 1.00 \\
Rsp/sec. & 0.56 & 0.56 & 0.55 & 0.00 \\
\hline
\end{tabular}

The large standard deviations appearing in the tahle suggest considerable difference in individua: $b u$.

Such differences in wild populations are probably more likely to occur than in inbred laboratory strains (Kavanau, 1963a; Veenstra, 1958)。

\section{Summary}

It is clear that deer mice can be conditioned to respond in a situation which provides detailed data on a selected sample of their behavior and at the same time does not require their capture nor a major modification of their natural habitat. It seems probable that with appropriate apparatus (Dice, 1962) the technique could be applied to a variety of animals and a variety of behaviors. Examples of the latter might indicate nest building in birds, pup retrieval in mice (Frieman, 1965), social interactions (Kavanau, 1963b), and other behaviors frequently studied by ethologists and ecologists. Such applications would provide relationships which could be compared with those determined from experimenter contrived laboratory responses. Further, these responses, e.g., bar pressing, when applied in the field would permit comparisons between the behavior of domesticated and wild species.

\section{References}

Dice, L. R. Laboratory instruments for measuring the behavior of shy or nocturnal small animals. J. Mammal., 1961, 42, 159-166.

Ferster, C. B., \& Skinner, B. F. Schedules of reinfarcement. New York: Appleton-Century-Crofts. 1957.

Frieman, Jeanne $\mathbf{P}$. The use of pups as positive reinforcement in mice. Paper read at American Psychological Association, Chicago, September, 1965.

Kavanau, J. L. Compulsory regime and control of environment in animal behavior. I wheel-running. Behaviour, 1963, 20, 251-281.

Kavanau, J. L. The study of social interaction between small animals. Anim. Behav., 1963, 11, 263-273.

Kavanaa, J. L. Behavior: confinement, adaptation, and compulsory regimes in laboratory studies. Science, 1964, 143, 490.

Schoenfeld, W. N., \& Baron, S. H. Ethology and experimental psychology. Science, 1965, 147, 634-635.

Veenstra, A. J. F. The behaviour of the multimammate mouse. Rattus (Mastomys) natalensis (A. Smith). Anim. Behav., 1958, 195-206. 